\title{
OPTIMALISASI PERAN GENDER DALAM UPAYA PENINGKATAN KESEJAHTERAAN NELAYAN.
}

\author{
Istiana, Hikmah dan Mursidin ${ }^{1}$
}

\begin{abstract}
ABSTRAK
Penelitian bertujuan untuk mengkaji peran gender pada rumah tangga melalui peningkatan pendapatan, optimalisasi peran gender dan kaitannya dengan pelaksanaan program pemberdayaan yang ada. Penelitian dilaksanakan di Kabupaten Lamongan (nelayan Brondong), Jawa Timur dan Kota Padang (nelayan Koto tangah) Sumatera Barat pada bulan april dan Juni 2007. Penelitian menggunakan metode survei (wawancara terstruktur) terhadap 60 rumah tangga dan diolah dengan analisis deskriptif. Keterlibatan istri nelayan Padang di sektor produktif menghasilkan pendapatan sedangkan istri nelayan Lamongan tidak karena dianggap membantu pekerjaan suami. Pada masyarakat nelayan Brondong, lakilaki memiliki beban lebih daripada perempuan, sebaliknya di padang, istri memiliki beban lebih dan beban ganda. Keputusan di sektor domestik di dominasi istri. Keputusan sektor produktif di Lamongan didominasi suami $(100 \%)$ sedangkan di Padang dilakukan secara bersama. Optimalisasi peran gender pada masyarakat nelayan Brondong perlu dilakukan melalui pelibatan peran perempuan sedangkan di Padang, peran suami dalam usaha pengolahan perlu dilibatkan. Gender merupakan konstruksi sosial budaya, gender tidaksehingga bersifat universal melainkan relatif pada konteks sosial budaya masyarakatnya. Arahan kebijakan yang sesuai untuk nelayan Brondong adalah pemberdayaan ekonomi perempuan karena mereka memiliki waktu luang 7,47 jam/hari (31,11\%). Sedangkan untuk masyarakat nelayan Padang, pemberdayaan lebih kearah peningkatan pemahaman konsep gender dalam mewujudkan kesejahteraan keluarga.
\end{abstract}

\section{Kata kunci: Peran Gender, Pemberdayaan.}

\section{Abstract : Optimalization of the Gender Role in Increasing Fishers' Prosperity. By: Istiana, Hikmah and Mursidin.}

This research aimed to analyze gender role in increasing familys properity through increasing income, optimalization gender role and relation with empowerment program. This research were done in Lamongan (Brondong fisheries), East Java and Padang (Koto tangah fisheries) West Sumatra on April and June 2007. The research used survey method of 60 families and processed by a descriptive analysis. Results of the study show that the Padang wife's fisheries involved in productive sector can generate income, but the situation was not happened in Lamongan because the wife's supposed helping husband's work only. In Brondong fisheries society, men have a more work-load than women. Women have a lot of work-load than men. In Lamongan, the decission for domestic sector is dominanted by wife and for productive sector is dominanted by husband (100\%). Decisions were made together. The optimalization gender role in Brondong fisheries society needs to be done by involving women's role. In Padang, men should be involved in the procesing industry. Gender was inclusive in the of social-culture contruction, so that gender is not universal, but relative in each society context. Suitable policy guidance for Brondong fisheries is to empowering women economic activity, because they have spare time for about 7,47 hours/day (31,11\%). Mean while for Padang fisheries society, empowerment should be directed to increase understanding gender concept to achieve the family's prosperity.

Keywords : Gender Role, Empowerments.

\section{PENDAHULUAN}

Nelayan merupakan kelompok masyarakat dengan tingkat kemiskinan yang lebih tinggi dibanding rata-rata penduduk lainnya. Dengan indikatornya kemiskinan yang dikaitkan dengan pendapatan 1 dollar AS per hari, kemiskinan masyarakat nelayan Tahun 2002 mencapai 32 \% (Satria, 2008).

\footnotetext{
1 Peneliti pada Balai Besar Riset Sosial Ekonomi Kelautan dan Perikanan 
Dengan kenaikan harga bahan bakar minyak (BBM) yang terjadi beberapa kali dalam periode Tahun 2005 s/d 2008, prosentase tersebut dipastikan telah meningkat sangat signifikan.

Kemiskinan nelayan tidak hanya terlihat pada ukuran absolutnya, melainkan juga tercermin dari kemampuan daya beli nelayan. Berdasarkan hasil penelitian Balai Besar Riset Sosial Ekonomi Kelautan dan Perikanan, kemampuan atau daya beli nelayan bahkan lebih rendah dibanding daya beli masyarakat yang bergerak pada sektor yang sama, yaitu masyarakat pembudidaya ikan. Sebagai contoh, rasio pendapatan dan pengeluaran (RPP) rumah tangga nelayan pelagis kecil yang beroperasi di perairan overfished adalah 1,32 , RPP nelayan pelagis kecil di perairan yang belum tereksploitasi berlebihan adalah 1,31 sedangkan nelayan udang penaid adalah 1,15 (Anonim, 2007). Sementara itu, RPP pembudidaya pada umumnya telah melebihi batas minimal yaitu 1,5; bahkan, beberapa kategori pembudidaya menunjukkan RPP lebih besar dari 2,5.

Sebuah kultur yang menganggap laki-laki sebagai satu-satunya pelaku ekonomi rumah tangga, atau sebaliknya mengasumsikan bahwa sektor produktif tertentu hanya dapat dilakukan oleh perempuan, merupakan sebuah budaya yang membentuk profil gender tertentu, yang pada gilirannya dapat berakibat pada pendapatan rendah. Kebijakan tertentu, misalnya yang mengandung substansi rekayasa sosial budaya dapat merubah profil gender semacam itu, yang apabila dapat diimplementasikan dengan baik maka akan dapat berdampak pada ekonomi masyarakat yang bersangkutan menjadi lebih sehat. Ini berarti bahwa pada dasarnya permasalahan kemiskinan kultural dapat ditransformasikan menjadi persoalan struktural, yang penanganannya pun diupayakan secara struktural.

Penelitian-penelitian terdahulu menunjukkan bahwa banyak kebijakan dan program pemerintah untuk pemberdayaan nelayan tidak berdampak maksimal karena kurang memanfaatkan peluang untuk mengoptimalkan peran gender. Sebagai contoh, menurut penelitian Balai Besar Riset Sosial Ekonomi Kelautan dan Perikanan (Anonim, 2007), disebutkan bahwa programprogram pemberdayaan nelayan pada umumnya hanya dibangun atas asumsiasumsi bahwa peningkatan pendapatan nelayan dapat terlaksana melalui penguatan aktivitas-aktvitas ekonomi yang dilakukan oleh kaum laki-laki. Sementara itu, pada bagian lain dari penelitian yang sama, disimpulkan bahwa banyak potensi perempuan / istri nelayan yang belum termanfaatkan dengan baik.

Berdasarkan di atas, kajian mengenai peran gender dalam rumah tangga dalam kaitannya dengan peningkatan pendapatan nelayan pada khususnya, dan kesejahteraan mereka pada umumnya, menjadi sangat relevan. Penelitian sebagaimana dilaporkan dalam makalah ini ditujukan untuk mengkaji aspek-aspek gender pada rumah tangga nelayan contoh, yaitu kasus Brondong (Kab Lamongan) dan Koto Tangah (Kota Padang), dan menarik kesimpulan tentang hal-hal yang dapat dijadikan dasar bagi terformulasikannya kebijakan baru dalam hal peningkatan pendapatan nelayan. Diantara aspek-aspek yang dikaji, aspek penting di antaranya adalah aspek penghambat dan penunjang strategi gender dalam rangka peningkatan pendapatan nelayan.

\section{METODOLOGI PENELITIAN}

\section{Waktu dan Lokasi Penelitian}

Penelitian ini dilaksanakan di Kabupaten Lamongan (Nelayan Brondong), Jawa Timur pada bulan April 2007 dan Kota Padang (Nelayan Koto tangah) Sumatera Barat pada bulan Juni 2007. Penentuan lokasi ini ditentukan secara sengaja dengan alasan bahwa lokasi tersebut mewakili lokasi yang menerima program bantuan modal yang responsif gender (Kota Padang) dengan lokasi yang menerima program bantuan modal yang 
tidak responsif gender (Lamongan). Lamongan dipilih karena merupakan sentra perikanan tangkap wilayah Jawa Timur.

\section{Metode Pengumpulan Data}

Jenis data yang diambil adalah data primer dan data sekunder. Data primer yang diambil meliputi karakteristik dan kegiatan individu dalam keluarga untuk melihat perbandingan peran gender dalam keluarga. Selain itu juga diambil data mengenai karakteristik masyarakat dan kondisi sosial budaya masyarakat yang dianut. Kondisi sosial budaya tersebut dipandang sebagai cerminan beberapa faktor utama untuk melihat aturan-aturan masyarakat yang berkaitan dengan peran gender. Data sekunder yang mendukung adalah data atau laporan hasil penelitian sebelumnya yang terkait dengan masalah pemberdayaan masyarakat pesisir.

Penelitian ini menggunakan metode survai dengan teknik wawancara langsung terhadap sumber data. Penggalian informasi mengenai profil kegiatan, akses dan kontrol terhadap sumberdaya dilakukan dengan wawancara terstruktur yaitu dengan menggunakan panduan pertanyaan (kuesioner) dan pengamatan langsung secara alami dalam kehidupan sehari-hari (naturalistic observation). Penentuan responden dilakukan secara purposif sesuai dengan tujuan penelitian. Sebanyak 60 keluarga menjadi responden terpilih dengan kriteria pemilihan atau mengutamakan responden yang terbuka dalam menjelaskan aktivitas mereka dalam keluarga dan masyarakat.

\section{Analisis Data}

Data yang diperoleh diolah dengan menggunakan analisis gender, yaitu proses yang dibangun secara sistematis untuk mengidentifikasi dan memahami pembagian kerja/peran laki-laki dan perempuan, akses dan kontrol terhadap sumber-sumber daya pembangunan, partisipasi dalam proses pembangunan dan manfaat yang mereka nikmati, pola hubungan antara laki-laki dan perempuan yang timpang, yang didalam pelaksanaannya memperhatikan faktor-faktor lainnya seperti kelas sosial, ras, dan suku bangsa (Anonimous, 2004).

Menurut Ervita dan Puji Utami (2007), gender tidak hanya meliputi pembedaan peran saja, tetapi juga mencakup pembedaan wilayah, status, dan pensifatan.

\section{a) Pembedaan peran dalam hal pekerjaan}

Misalnya, laki-laki dianggap pekerja produktif dan perempuan pekerja reproduktif. Kerja produktif adalah jenis pekerjaan yang menghasilkan uang (dibayar). Kerja reproduktif adalah kerja yang menjamin pengelolaan dan reproduksi (termasuk di dalamnya adalah mengurusi pekerjaan rumah tangga dan mengasuh anak).

\section{b) Pembedaan wilayah kerja}

Misalnya, laki-laki berada di wilayah publik (di luar rumah) dan perempuan berada di wilayah domestik (di dalam rumah/ruang pribadi).

\section{c) Pembedaan status}

Misalnya, laki-laki berperan sebagai subyek, sebagai aktor utama, dan perempuan sebagai obyek atau pemain figuran (pelengkap).

\section{d) Pembedaan sifat}

Misalnya, perempuan dilekati dengan sifat dan atribut feminin misalnya halus, sopan, kasih sayang, cengeng, penakut, emosional, "cantik", memakai perhiasan dan cocoknya berkain panjang atau rok. Sementara laki-laki dilekati sifat maskulin misalnya, kuat, berani, keras, rasional, kasar, gagah, tegas, berotot dan aktif. Sifat ini bisa di pertukarkan.

Analisis data yang digunakan adalah analisis deskriptif dengan tujuan untuk menjelaskan data aktual yang didapat secara mendalam meliputi: 1). Profil kegiatan (siapa melakukan apa); 2). Profil akses dan kontrol terhadap sumberdaya (siapa memiliki dan memutuskan apa); 3). Evaluasi profil kegiatan keluarga yang mempengaruhi akses dan kontrol dalam keluarga. 


\section{HASIL DAN PEMBAHASAN}

\section{Kondisi Dan Potensi Perikanan Laut}

Usaha penangkapan ikan laut di Kabupaten Lamongan terpusat di perairan Laut Jawa pada wilayah Kecamatan Brondong dan Kecamatan Paciran yang memiliki 5 (lima) Tempat Pendaratan Ikan (TPI), yaitu mulai dari arah timur ke barat (Weru, Kranji, Brondong, Labuhan dan Lohgung). Dilihat dari produksinya paling tinggi adalah Pelabuhan Perikanan Nusantara Brondong yang mencapai kurang lebih 100 ton/hari, dibandingkan dengan keempat pangkalan pendaratan ikan yang lain (Weru, Kranji, Labuhan dan Lohgung) yang hanya mencapai 10 ton/hari (Anonymous, 2006).

Berdasarkan hasil survei diketahui jenis alat tangkap yang dioperasikan di Kabupaten Lamongan yaitu purse seine, payang, gillnet, tramel net, pancing prawe dan lainnya. Alat tangkap yang dominan adalah alat tangkap payang karena pengoperasiannya sesuai dengan kondisi di perairan laut utara Jawa, namun jika dilihat dari nilai produktivitas yang tertinggi adalah alat tangkap purse seine. Tipe kapal yang ada rata-rata adalah tipe perahu ijo-ijo dengan bentuk dasar $U$ dan tipe purse seine serta sebagian kecil menggunakan kapal motor dengan tipe skoci.

Alat tangkap yang digunakan oleh nelayan Padang antara lain: tonda, Payang, Gillnet dan Pancing. Kapal motor paling banyak dioperasikan (518 unit), sedangkan perahu tanpa motor (PTM) 354 unit dan perahu motor tempel (PMT) 427 unit. Total produksi ikan di Kota Padang sebanyak 14.000 ton/tahun sedangkan kebutuhan ikan 20.000 ton/tahun (asumsi tingkat konsumsi 25 $\mathrm{kg} / \mathrm{kapita} / \mathrm{tahun}$ ), jadi kekurangan 6.000 ton tahun, kekurangan tersebut dipasok dari Kabupaten Pesisir Selatan, Kabupaten Padang Pariaman serta dari propinsi tetangga yaitu Medan (Sibolga) dan komoditas yang potensial adalah ikan tuna, kerapu dan kepiting. Komoditas ekspor untuk Sumatera Barat dalah tuna bisa mencai 100 ton pertahun sedangkan kebutuhan Jepang dan negaranegara lain seperti Singapura, Korea, Hongkong sebesar 200.000 ton per tahun, jadi pasar ekspor masih terbuka luas. Potensi perikanan yang dimiliki perairan Lamongan dan Padang sudah cukup untuk dijadikan lahan mencari penghidupan/pendapatan.

Pendapatan nelayan tidaklah pasti setiap bulannya, hal ini di sebabkan oleh kondisi musim dan alam yang ada di perairan. Pada saat musim ikan, nelayan mendapatkan hasil tangkapan yang berlimpah sehingga pendapatan yang diterimapun juga meningkat. Sedangkan pada musim paceklik, pendapatan nelayan menurun. Selain faktor musim, hasil tangkapan juga dipengaruhi oleh alat tangkap yang digunakan nelayan. Sebanyak $96,67 \%$ perempuan nelayan Padang bekerja di sektor perikanan sedangkan hanya $10 \%$ perempuan nelayan Brodong yang terlibat di sektor produktif. Sebaran tingkat pendapatan dapat dijelaskan pada Tabel 1.

Modal merupakan hal penting dalam melakukan setiap usaha, nelayan juga membutuhkan modal untuk usaha penangkapannya. Pada nelayan Brondong yang memiliki aneka ragam alat tangkap, tentu berpengaruh pada besar kecilnya modal yang dibutuhkan. Modal tertinggi pada alat tangkap Purse seine dan pancing. Aset produktif nelayan padang tergolong rendah karena menggunakan alat tangkap gillnet dan mini purse seine dengan ukuran kapal di bawah 10GT.

\section{Profil Kegiatan (Aktivitas) Gender Dalam Keluarga dan Masyarakat}

Profil kegiatan ini melihat pembagian kerja antara laki-laki dan perempuan dalam keluarga. Pembagian kerja dibedakan menjadi 3 , yaitu kegiatan reproduksi atau rumah tangga (domestik), kegiatan produksi dan kegiatan sosial. Keterlibatan istri nelayan Padang di sektor produktif menghasilkan pendapatan sedangkan istri nelayan Lamongan tidak menghasilkan pendapatan karena dianggap membantu pekerjaan suami. 
Tabel 1. Tingkat Pendapatan Responden di Kabupaten Lamongan dan Kota Padang, 2007. Table 1. Respondent Income Level in the Lamongan District dan Padang, 2007.

\begin{tabular}{|c|c|c|c|c|}
\hline \multirow[b]{2}{*}{$\begin{array}{l}\text { Kisaran Rata-rata Pendapatan } \\
\text { (Rp/bulan)/ Range Of Income } \\
\text { Average (IRD/Month) }\end{array}$} & \multicolumn{2}{|c|}{ Lamongan } & \multicolumn{2}{|c|}{ Padang } \\
\hline & $\begin{array}{c}\text { Suami } \\
\text { (orang\&\%)/ } \\
\text { Husband } \\
\text { (person \& \%) }\end{array}$ & $\begin{array}{c}\text { Istri } \\
\text { (orang\&\%)/ } \\
\text { Wife (person } \\
\& \% \text { ) }\end{array}$ & $\begin{array}{l}\text { Suami } \\
\text { (orang\&\%)/ } \\
\text { Husband } \\
\text { (person \& \%) }\end{array}$ & $\begin{array}{c}\text { Istri } \\
\text { (orang\&\%)/ } \\
\text { Wife (person \& } \\
\% \text { o) }\end{array}$ \\
\hline $\begin{array}{l}\text { Tidak berpenghasilan/ No } \\
\text { income }\end{array}$ & 0 & $27(90)$ & 0 & $1(3,33)$ \\
\hline$<\operatorname{Rp} 800.000,-$ & $6(20)$ & 0 & $5(16,67)$ & $16(53,33)$ \\
\hline $\operatorname{Rp} 800.000,--\operatorname{Rp} 1.200 .000$ & $9(30)$ & $3(10)$ & $11(36,67)$ & $2(6.67)$ \\
\hline $\operatorname{Rp} 1.200 .000,--\operatorname{Rp} 1.600 .000,-$ & $4(13,33)$ & 0 & $14(46,67)$ & $10(33,33)$ \\
\hline Rp 1.600.000,- - Rp 2.000.000,- & $5(16,67)$ & 0 & 0 & $1(3,33)$ \\
\hline$>$ Rp 2.000.000,- & $6(20)$ & 0 & 0 & 0 \\
\hline
\end{tabular}

Sumber : Data Primer Diolah, 2007/Source : Primary Data Processed, 2007.

Tabel 2. Nilai Aset Produktif Responden di Kabupaten Lamongan dan Kota Padang, 2007. Table 2. Respondent Productive Asset Value in the Lamongan District and Padang , 2007.

\begin{tabular}{ccrr}
\hline \multirow{2}{*}{ No. } & Nilai aset (Rp) / Asset Value & Jumlah Responden / Number of Responden (n/\%) \\
\cline { 3 - 4 }$(I R D)$ & Lamongan & Padang \\
\hline 1. & $<57.317 .000$ & $13(43,33)$ & $30(100)$ \\
2. & $57.317 .000-114.634 .000$ & $7(23,34)$ & $0(0,00)$ \\
3. & $>114.635 .000$ & $10(33,33)$ & $0(0,00)$ \\
& Total & $30(100)$ & $30(100)$ \\
\hline
\end{tabular}

Sumber : Data Primer Diolah, 2007/Source : Primary Data Processed, 2007.

Waktu luang lebih banyak dimiliki oleh istri nelayan Brondong dan nelayan Padang yang dapat dilihat pada Tabel 3. Pada masyarakat nelayan Brondong, terlihat laki-laki memiliki beban lebih daripada perempuan, sebaliknya pada masyarakat nelayan Padang justru istri memiliki beban lebih dan beban ganda.

\section{Profil Akses dan Kontrol}

Akses adalah suatu kesempatan atau peluang yang diperoleh untuk menggunakan atau memanfaatkan sumberdaya. Memiliki kesempatan belum tentu berarti memiliki wewenang untuk mengambil keputusan secara penuh terhadap sumberdaya. Kontrol

\section{Tabel 3. Curahan Waktu terhadap Profil Kegiatan Responden di Kabupaten Lamongan dan} Kota Padang, 2007.

Table 3. Spending Time of Respondent Activity Profile in the Lamongan District and Padang, 2007.

\begin{tabular}{|c|c|c|c|c|c|}
\hline \multirow{3}{*}{ No } & \multirow{3}{*}{$\begin{array}{c}\text { Profil Kegiatan / Activity } \\
\text { Profile }\end{array}$} & \multicolumn{4}{|c|}{ Curahan Waktu / Spent Time } \\
\hline & & \multicolumn{2}{|c|}{ Lamongan } & \multicolumn{2}{|c|}{ Padang } \\
\hline & & $\begin{array}{c}\text { Suami/ } \\
\text { Husband (\%) }\end{array}$ & $\begin{array}{c}\text { Istri/ Wife } \\
(\%)\end{array}$ & $\begin{array}{c}\text { Suami/ } \\
\text { Husband (\%) }\end{array}$ & Istri/ Wife (\%) \\
\hline 1. & $\begin{array}{l}\text { Kegiatan produktif } \\
\text { (jam/hari)/Productive } \\
\text { activity (hours/day) }\end{array}$ & $\begin{array}{r}11,1 \\
(46,25)\end{array}$ & $\begin{array}{r}3,17 \\
(13,21)\end{array}$ & $\begin{array}{r}10,90 \\
(45,42)\end{array}$ & $\begin{array}{r}5,55 \\
(23,13)\end{array}$ \\
\hline
\end{tabular}


Tabel 3. lanjutan/ Table 3. continued

\begin{tabular}{|c|c|c|c|c|c|}
\hline \multirow{3}{*}{ No } & \multirow{3}{*}{$\begin{array}{c}\text { Profil Kegiatan / Activity } \\
\text { Profile }\end{array}$} & \multicolumn{4}{|c|}{ Curahan Waktu / Spent Time } \\
\hline & & \multicolumn{2}{|c|}{ Lamongan } & \multicolumn{2}{|c|}{ Padang } \\
\hline & & $\begin{array}{c}\text { Suami/ } \\
\text { Husband }(\%)\end{array}$ & $\begin{array}{c}\text { Istri/ Wife } \\
(\%)\end{array}$ & $\begin{array}{c}\text { Suami/ } \\
\text { Husband (\%) }\end{array}$ & Istri/ Wife (\%) \\
\hline 2. & $\begin{array}{l}\text { Kegiatan domestik } \\
\text { (jam/hari)/ Domestic } \\
\text { activity (hours/day) }\end{array}$ & $\begin{array}{r}1,3 \\
(5,42)\end{array}$ & $\begin{array}{r}3,57 \\
(14,88)\end{array}$ & $\begin{array}{r}0,39 \\
(1,63)\end{array}$ & $\begin{array}{r}6,91 \\
(28,79)\end{array}$ \\
\hline 3. & $\begin{array}{l}\text { Kebutuhan dasar } \\
\text { keluarga (jam/hari)/ } \\
\text { Basic family need } \\
\text { (hours/day) }\end{array}$ & $\begin{array}{r}7,24 \\
(30,19)\end{array}$ & $\begin{array}{r}8,32 \\
(34,65)\end{array}$ & $\begin{array}{r}7,24 \\
(30,15)\end{array}$ & $\begin{array}{r}7,60 \\
(31,68)\end{array}$ \\
\hline 4. & $\begin{array}{l}\text { Aktivitas/Kkgiatan Sosial } \\
\text { (jam/hari)/ Social activity } \\
\text { (hours/day) }\end{array}$ & $\begin{array}{r}1,96 \\
(8,17)\end{array}$ & $\begin{array}{r}1,48 \\
(6,17)\end{array}$ & $\begin{array}{r}0,67 \\
(2,79)\end{array}$ & $\begin{array}{r}0,83 \\
(3,46)\end{array}$ \\
\hline 5. & $\begin{array}{l}\text { Waktu luang (jam/hari)/ } \\
\text { Spare time (h/day) }\end{array}$ & $\begin{array}{r}2,4 \\
(10)\end{array}$ & $\begin{array}{r}7,47 \\
(31,11)\end{array}$ & $\begin{array}{r}4,80 \\
(20)\end{array}$ & $\begin{array}{r}3,11 \\
(12,96)\end{array}$ \\
\hline
\end{tabular}

Sumber : Data Primer Diolah, 2007/Source : Primary Data Processed, 2007.

adalah penguasaan atau wewenang dalam mengambil keputusan, dalam hal ini seseorang telah memiliki wewenang yang penuh untuk mengambil suatu keputusan.

Secara kuantitatif profil akses dan kontrol pada masyarakat nelayan di kedua lokasi terdapat pada tabel 4 dan 5. Pada kegiatan domestik, pengambilan keputusan dalam penyediaan menu pada nelayan padang dan lamongan merupakan mutlak keputusan istri. Keputusan dalam tabungan dan hal kesehatan keluarga nelayan Padang didominasi oleh istri $(66,66 \%)$.

Keputusan terhadap kegiatan produktif (pengelolaan usaha perikanan) pada nelayan Lamongan adalah mutlak dilakukan suami $(100 \%)$. Berbeda dengan nelayan Padang, pengelolaan usaha perikanan ada campur tangan istri walaupun masih dominan suami $(56,66)$. Tetapi dalam hal pengelolaan usaha pengolahan di Kota Padang di dominasi oleh istri $(63,33 \%)$. Sedangkan istri nelayan

\section{Tabel 4. Pengambilan Keputusan dalam Aktifitas Domestik Responden di Kabupaten Lamongan dan Kota Madang, 2007}

Table 4. Decisión Making in Domestic Respondent Activities in the Lamongan District and Padang, 2007.

$$
\mathrm{n}(\%)
$$

\begin{tabular}{|c|c|c|c|c|c|c|c|}
\hline \multirow[t]{2}{*}{ No } & \multirow[t]{2}{*}{$\begin{array}{l}\text { Aktifitas Domestik/ } \\
\text { Domestic Activity }\end{array}$} & \multicolumn{2}{|c|}{$\begin{array}{c}\text { Dominasi Istri/ Wife } \\
\text { Domination }\end{array}$} & \multicolumn{2}{|c|}{$\begin{array}{c}\text { Suami + Istri/ } \\
\text { Husband + Wife }\end{array}$} & \multicolumn{2}{|c|}{$\begin{array}{c}\text { Dominasi Suami/ } \\
\text { Husband Domination }\end{array}$} \\
\hline & & Lamongan & Padang & Lamongan & Padang & Lamongan & Padang \\
\hline 1 & $\begin{array}{l}\text { Peny } \\
\text { maka } \\
\text { servir }\end{array}$ & $\begin{array}{r}30 \\
(100)\end{array}$ & $\begin{array}{r}30 \\
(100)\end{array}$ & 0 & 0 & 0 & \\
\hline 2 & $\begin{array}{l}\text { Pendidikan anak/ } \\
\text { Children education }\end{array}$ & 0 & $\begin{array}{r}8 \\
(26,66) \\
\end{array}$ & $\begin{array}{r}21 \\
(70)\end{array}$ & $\begin{array}{r}21 \\
(70)\end{array}$ & $\begin{array}{r}9 \\
(30) \\
\end{array}$ & $(3,33)$ \\
\hline
\end{tabular}


Tabel 4. Ianjutan/ Table 4. continued

\begin{tabular}{|c|c|c|c|c|c|c|c|}
\hline \multirow{3}{*}{ No } & \multirow{3}{*}{$\begin{array}{l}\text { Aktifitas Domestik/ } \\
\text { Domestic Activity }\end{array}$} & \multicolumn{6}{|c|}{ n (\%) } \\
\hline & & \multicolumn{2}{|c|}{$\begin{array}{c}\text { Dominasi Istri/ Wife } \\
\text { Domination }\end{array}$} & \multicolumn{2}{|c|}{$\begin{array}{c}\text { Suami + Istri/ } \\
\text { Husband + Wife }\end{array}$} & \multicolumn{2}{|c|}{$\begin{array}{c}\text { Dominasi Suami/ } \\
\text { Husband Domination }\end{array}$} \\
\hline & & Lamongan & Padang & Lamongan & Padang & Lamongan & Padang \\
\hline 3 & $\begin{array}{l}\text { Kesehatan } \\
\text { anggota keluarga/ } \\
\text { Family health }\end{array}$ & $7(23,33)$ & $\begin{array}{r}10 \\
(66,66)\end{array}$ & $\begin{array}{r}14 \\
(46,67)\end{array}$ & $\begin{array}{r}18 \\
(60)\end{array}$ & $\begin{array}{r}9 \\
(30)\end{array}$ & $2(6,66)$ \\
\hline 4 & $\begin{array}{l}\text { Tabungan } \\
\text { keluarga/ Family } \\
\text { saving }\end{array}$ & $\begin{array}{r}2 \\
(6,67)\end{array}$ & $\begin{array}{r}10 \\
(66,66)\end{array}$ & $\begin{array}{r}28 \\
(93,33)\end{array}$ & $\begin{array}{r}18 \\
(60)\end{array}$ & $\begin{array}{r}2 \\
(6,67)\end{array}$ & $2(6,66)$ \\
\hline 5 & $\begin{array}{l}\text { Pengadaan } \\
\text { peralatan rumah } \\
\text { Tangga/ } \\
\text { Household } \\
\text { equipment supply }\end{array}$ & 0 & $\begin{array}{r}9 \\
(30)\end{array}$ & $\begin{array}{r}10 \\
(33,33)\end{array}$ & $\begin{array}{r}15 \\
(50)\end{array}$ & $\begin{array}{r}20 \\
(66,67)\end{array}$ & $\begin{array}{r}6 \\
(20)\end{array}$ \\
\hline 6 & $\begin{array}{l}\text { Reproduksi/ } \\
\text { Reproduction }\end{array}$ & $\begin{array}{r}2 \\
(6,67) \\
\end{array}$ & $\begin{array}{r}7 \\
(23,33) \\
\end{array}$ & $\begin{array}{r}25 \\
(83,33) \\
\end{array}$ & $\begin{array}{r}23 \\
(76,66) \\
\end{array}$ & 0 & 0 \\
\hline
\end{tabular}

Sumber : Data Primer Diolah, 2007/Source : Primary Data Processed, 2007.

Tabel 5. Pengambilan Keputusan dalam Aktifitas Publik Responden di Kabupaten Lamongan dan Kota Padang, 2007.

TTable 5. Decisión Making in Respondent's Public Activities in the Lamongan District and Padang, 2007.

\begin{tabular}{|c|c|c|c|c|c|c|c|}
\hline \multirow{3}{*}{ No. } & \multirow{3}{*}{$\begin{array}{l}\text { Aktifitas Produktif/ } \\
\text { Productive Activitty }\end{array}$} & \multicolumn{6}{|c|}{ n (\%) } \\
\hline & & \multicolumn{2}{|c|}{$\begin{array}{c}\text { Dominasi Istri/ Wife } \\
\text { Domination }\end{array}$} & \multicolumn{2}{|c|}{$\begin{array}{c}\text { Suami + Istri/ } \\
\text { Husband+ Wife }\end{array}$} & \multicolumn{2}{|c|}{$\begin{array}{c}\text { Dominasi Suami/ } \\
\text { Husband Domination }\end{array}$} \\
\hline & & Lamongan & Padang & Lamongan & Padang & Lamongan & Padang \\
\hline 1 & $\begin{array}{lr}\begin{array}{l}\text { Modal } \\
\text { perikanan/ } \\
\text { investment }\end{array} & \text { Fisheries } \\
\end{array}$ & 0 & $\begin{array}{r}13 \\
(43,33)\end{array}$ & $\begin{array}{r}16 \\
(53,33)\end{array}$ & $\begin{array}{r}14 \\
(46.66)\end{array}$ & $\begin{array}{r}14 \\
(46,67)\end{array}$ & $\begin{array}{r}3 \\
(10)\end{array}$ \\
\hline 2 & $\begin{array}{l}\text { Pengelolaan usaha } \\
\text { perikanan/ Fisheries } \\
\text { business management }\end{array}$ & 0 & $\begin{array}{r}2 \\
(6,66)\end{array}$ & 0 & $\begin{array}{r}11 \\
(36,66)\end{array}$ & $\begin{array}{r}30 \\
(100)\end{array}$ & $\begin{array}{r}17 \\
(56,66)\end{array}$ \\
\hline 3 & $\begin{array}{l}\text { Pengelolaan usaha } \\
\text { pengolahan/ } \\
\text { Processing business } \\
\text { management }\end{array}$ & 0 & $\begin{array}{r}19 \\
(63,33)\end{array}$ & 0 & $\begin{array}{r}11 \\
(36,66)\end{array}$ & 0 & 0 \\
\hline 4 & $\begin{array}{l}\text { Usaha non peri-kanan/ } \\
\text { Non fisheries business } \\
\text { management }\end{array}$ & 0 & $\begin{array}{r}2 \\
(6,66)\end{array}$ & $\begin{array}{r}3 \\
(10)\end{array}$ & $\begin{array}{r}21 \\
(70)\end{array}$ & $\begin{array}{r}20 \\
(66,67)\end{array}$ & $\begin{array}{r}7 \\
(23,33)\end{array}$ \\
\hline 5 & $\begin{array}{l}\text { Sosial } \\
\text { kemasyarakatan/ } \\
\text { Social community }\end{array}$ & $\begin{array}{r}1 \\
(3,33)\end{array}$ & $\begin{array}{r}5 \\
(16,66)\end{array}$ & $\begin{array}{r}22 \\
(73,33)\end{array}$ & $\begin{array}{r}20 \\
(66,66)\end{array}$ & $\begin{array}{r}1 \\
(3,33)\end{array}$ & $\begin{array}{r}5 \\
(16,66) \\
\end{array}$ \\
\hline
\end{tabular}

Sumber : Data Primer Diolah, 2007/Source : Primary Data Processed, 2007. 
Brondong berkontribusi pada usaha non perikanan $(66,67 \%)$.

\section{Pengaruh Kondisi Sosial Ekonomi dan Budaya Masyarakat Nelayan}

Masyarakat nelayan di kedua lokasi penelitian menunjukkan adanya kapasitas untuk menerima konsep atau pengetahuan yang datang dari luar. Sebagai contoh, para nelayan pada umumnya telah memahami wilayah perairan yang dijadikan lahan penangkapan, berikut alat tangkap sesuai dengan kondisi perairan tersebut. Masyarakat juga memahami pentingnya konsep kelestarian lingkungan sumberdaya, seperti tercermin dari berjalannya berbagai peraturan tentang penggunaan alat tangkap.

Namun, hal tersebut belum tercermin pada masalah gender. Persepsi peran gender pada masyarakat nelayan masih belum dipahami secara mendalam. Hasil wawancara dengan responden menunjukkan masih adanya anggapan pembagian tugas rumah tangga berdasarkan seks dan fisik laki-laki dan perempuan. Selain tertuang pada respon wawancara, hal ini juga tergambarkan pada kehidupan sehari-hari, dimana tugas laki-laki cenderung terarah pada sektor produktif sedangkan perempuan pada sektor domestik. Kondisi yang lebih nyata ditemukan pada kasus Brondong; untuk kasus Koto Tangah, disamping melakukan tugas domestiknya, hampir semua responden perempuan nelayan juga terlibat aktif di sektor produktif.

Secara intuitif, kapasitas untuk menerima konsep, ide atau pengetahuan dari luar pada umumnya dipengaruhi oleh beberapa faktor sosial, termasuk di antaranya tuntutan ekonomi keluarga, tingkat pendidikan, dsb. Namun demikian, dari hasil pengamatan, pengaruh-pengaruh tidak tertangkap secara signifikan pada kasus di kedua lokasi. Sebanyak 63\% nelayan Koto Tangah memiliki satu anak dan 60\% nelayan Brondong memiliki 2-3 anak (Tabel 6). Lebih lanjut, menurut responden jumlah anggota keluarga harus direncanakan secara matang karena pertimbangan kemampuan ekonomi yang mempengaruhi kesejahteraan keluarga. Lebih jauh, data menunjukkan bahwa tingkat pendidikan istri nelayan Brondong lebih tinggi dibanding di Koto Tangah (Tabel 7). Fakta menyangkut dua variabel sosial tersebut seharusnya mengarah pada pemahaman yang baik pada masyarakat istri nelayan Brondong dalam banyak hal, termasuk mengenai masalah gender, yang seharusnya pula termanifestasikan dalam keterlibatan istri yang lebih besar pada kegiatan usaha.

Salah satu data yang dapat menjelaskan gejala seperti tercermin pada Tabel 6 dan Tabel 7 di atas adalah bahwa di Koto Tangah masyarakat mendapatkan imbas dari kebijakan yang lebih responsif gender. Dengan pembinaan usaha yang diarahkan pada dan terkait dengan 'pembedaan sifat', perempuan / istri nelayan di lokasi tersebut menemukan fungsi yang lebih tepat dalam usaha perikanan. Hal ini kemudian berdampak pada pekerjaan-pekerjaan yang lebih berkarakter perempuan; struktur yang terbentuk sebagai akibatnya terdiri dari

Tabel 6. Jumlah Anggota Keluarga Responden di Lamongan dan Kota Padang, 2007. Table 6. Number of Respondent's Family Members in the Lamongan District and Padang , 2007.

\begin{tabular}{ccrr}
\hline \multirow{2}{*}{ No } & Jumlah Anggota Keluarga ( orang)/ & \multicolumn{2}{c}{$\mathrm{n}(\%)$} \\
\cline { 3 - 4 } & Amount of Member's Family (man) & Lamongan & Padang \\
\hline 1 & $<3$ & $9(30)$ & $19(63,33)$ \\
2 & $4-5$ & $18(60)$ & $6(20,00)$ \\
3 & $>5$ & $3(10)$ & $5(16,67)$ \\
& Jumlah & $30(100)$ & $\mathbf{3 0}(100)$ \\
\hline
\end{tabular}

Sumber : Data Primer Diolah, 2007/Source : Primary Data Processed, 2007. 
Tabel 7. Tingkat Pendidikan Responden di Kabupaten Lamongan dan Kota Padang, 2007.

Table 7. Education Level of Respondent in the Lamongan District and Padang, 2007.

\begin{tabular}{|c|c|c|c|c|c|}
\hline \multirow[b]{2}{*}{ No. } & \multirow[b]{2}{*}{ Kategori / Category } & \multicolumn{2}{|l|}{ Lamongan } & \multicolumn{2}{|c|}{ Padang } \\
\hline & & $\begin{array}{l}\text { Suami / Husband } \\
\text { (n \&\%) }\end{array}$ & $\begin{array}{c}\text { Istri / } \\
\text { Wife } \\
\text { (n \&\%) }\end{array}$ & $\begin{array}{l}\text { Suami / } \\
\text { Husband } \\
\text { (n \&\%) }\end{array}$ & $\begin{array}{c}\text { Istri / } \\
\text { Wife } \\
\text { (n \&\%) }\end{array}$ \\
\hline 1 & Tidak Sekolah/ Uneducated & $\begin{array}{r}1 \\
(3,33)\end{array}$ & $\begin{array}{r}1 \\
(3,33)\end{array}$ & 0 & 0 \\
\hline 2 & $\begin{array}{l}\text { Tidak Tamat SD / Primary } \\
\text { school drop out }\end{array}$ & $\begin{array}{r}3 \\
(10)\end{array}$ & $\begin{array}{r}4 \\
(13,33)\end{array}$ & $\begin{array}{r}15 \\
(50)\end{array}$ & $\begin{array}{r}10 \\
(33,33)\end{array}$ \\
\hline 3 & $\begin{array}{l}\text { Tamat SD / Primary school } \\
\text { graduate }\end{array}$ & $\begin{array}{r}17 \\
(56,67)\end{array}$ & $\begin{array}{r}12 \\
(40)\end{array}$ & $\begin{array}{r}10 \\
(33,33)\end{array}$ & $\begin{array}{r}9 \\
(30)\end{array}$ \\
\hline 4 & $\begin{array}{l}\text { Tidak Tamat SLTP / Junior } \\
\text { High School drop out }\end{array}$ & $\begin{array}{r}1 \\
(3,33)\end{array}$ & $\begin{array}{r}3 \\
(10)\end{array}$ & 0 & $\begin{array}{r}4 \\
(13,33)\end{array}$ \\
\hline 5 & $\begin{array}{l}\text { Tamat SLTP / Junior High } \\
\text { School graduate }\end{array}$ & $\begin{array}{r}5 \\
(16,67)\end{array}$ & $\begin{array}{r}8 \\
(26,67)\end{array}$ & $\begin{array}{r}2 \\
(6,67)\end{array}$ & $\begin{array}{r}2 \\
(6,67)\end{array}$ \\
\hline 6 & $\begin{array}{l}\text { Tidak Tamat SLTA / Senior } \\
\text { High School drop out }\end{array}$ & $\begin{array}{r}1 \\
(3,33)\end{array}$ & $\begin{array}{r}1 \\
(3,33)\end{array}$ & $\begin{array}{r}3 \\
(10)\end{array}$ & $\begin{array}{r}2 \\
(6,67)\end{array}$ \\
\hline 7 & $\begin{array}{l}\text { Tamat SLTA / Senior High } \\
\text { School graduate }\end{array}$ & $\begin{array}{r}2 \\
(6,67)\end{array}$ & $\begin{array}{r}1 \\
(3,33)\end{array}$ & 0 & $\begin{array}{r}3 \\
(10)\end{array}$ \\
\hline 8 & $\begin{array}{l}\text { Tidak Tamat PT / University } \\
\text { drop out }\end{array}$ & 0 & 0 & 0 & 0 \\
\hline 9 & $\begin{array}{l}\text { Tamat PT / University } \\
\text { graduate }\end{array}$ & 0 & 0 & 0 & 0 \\
\hline & Total & $\begin{array}{r}30 \\
(100)\end{array}$ & $\begin{array}{r}30 \\
(100) \\
\end{array}$ & $\begin{array}{r}30 \\
(100)\end{array}$ & $\begin{array}{r}30 \\
(100) \\
\end{array}$ \\
\hline
\end{tabular}

Sumber : Data Primer Diolah, 2007/Source : Primary Data Processed, 2007.

komponen pekerjaan bakul ikan (20\%), pedagang ikan olahan $13 \%$, pengolah ikan $30 \%$ dan lainnya (non perikanan) $23 \%$. Responsif gender Di Brondong, sebaliknya, dengan tidak adanya kebijakan yang responsif gender, hanya terdapat $10 \%$ istri nelayan yang berpenghasilan, yang kesemuanya berprofesi sebagai bakul ikan.

\section{Optimalisasi Peran Gender Pada Rumah Tangga Nelayan}

Pemberdayaan masyarakat pesisir dilaksanakan dengan cara meningkatkan akses masyarakat terhadap modal, manajemen usaha, pasar, dan teknologi. Selain itu juga masyarakat diarahkan untuk mampu mengoptimalkan aksi kolektif dalam bentuk partisipasi, pengembangan organisasi, pengembangan kelompok, pengembangan sistem, serta pengembangan regulasi di antara mereka yang memberi dampak bagi kesejahteraan individu.

Pemberdayaan masyarakat dalam hal ini tidak saja pemberdayaan kaum laki-laki namun juga perempuan dalam konteks keluarga. Alasan yang mendasari sangatlah konkret dimana dalam lingkungan nelayan jumlah penduduk perempuan cukup besar. Dan menggantungkan hidupnya baik secara ekonomis maupun ekologis terhadap sumberdaya perairan baik secara langsung maupun tidak langsung.

Gender adalah konsep tentang peran dan tanggung jawab perempuan dan laki-laki yang dikonstruksikan oleh masyarakat. Peran dan tanggung jawab yang dikonstruksikan masyarakat tersebut seringkali timpang dan tidak adil. Oleh sebab itu, diperlukan berbagai 
upaya untuk mewujudkan kesetaraan dan keadilan gender. Negara kita telah menetapkan strategi untuk mewujudkan kesetaraan dan keadilan gender dengan cara memasukkan atau mengintegrasikan aspek gender di dalam proses pembangunan nasional. Strategi tersebut disebut pengarusutamaan gender (gender mainstreaming), yang disingkat sebagai PUG dan pelaksanaannya diperkuat oleh Instruksi Presiden Nomor 9 Tahun 2000, selain itu ada landasan hukum lain yang mendukung upaya pemberdayaan perempuan termasuk wanita nelayan adalah:

a) Instruksi Presiden RI Nomor 5 tahun 1995 tentang Peningkatan Peranan perempuan dalam Pembangunan Daerah.

b) Instruksi Menteri Dalam Negeri Nomor 17 Tahun 1996 tentang Petunjuk Teknis Pelaksanaan Pengelolaan Program Peningkatan Peranan Perempuan Peranan perempuan dalam Pembangunan di Daerah. (Anonimous,2002.)

\section{Arahan Kebijakan}

Wacana pemberdayaan ekonomi perempuan banyak masuk melalui program pemberdayaan ekonomi nelayan. Walaupun secara khusus belum ditujukan untuk meningkatkan independensi perempuan. Diharapkan pendekatan yang digunakan dalam program-program pemberdayaan perempuan untuk meningkatkan akses dan kontrol perempuan terhadap sumberdaya ekonomi di tingkat rumah tangga (ruang domestik) dan di tingkat komunitas (ruang publik).

Karena gender merupakan konstruksi sosial budaya maka gender tidak universal atau seragam melainkan relatif pada konteks sosial budaya masyarakatnya. Setiap perkembangan apa pun bentuknya akan diikuti dengan perubahan sosial yang lain, karena erat kaitannya dengan keadaan yang dimiliki manusia sendiri. Dalam kehidupan masyarakat selalu terjadi hubungan antara individu dengan individu, individu dengan kelompok serta individu dengan antar kelompok, dalam masyarakat yang menyebabkan dinamika dan suatu perubahan.

Pelibatan perempuan pesisir dalam pembentukan kelompok pengajian, simpan pinjam, dan arisan menunjukkan bahwa perempuan terlibat di sektor publik. Kelompok pengajian, arisan dll merupakan kelompokkelompok yang telah teruji soliditasnya, sehingga sentuhan program dan kebijakan yang tidak terlalu besar dapat diharapkan berkembang menjadi sesuatu yang berdampak signifikan. Situasi di lapangan mengindikasikan bahwa hal ini merupakan suatu yang realistis; di masyarakat nelayan Brondong, misalnya, kaum perempuan sebenarnya telah terkondisikan dengan pranata-pranata sosial seperti itu untuk berbagai aktivitas yang berfungsi ganda. Salah satunya adalah fungsi yang mengarah pada perannya untuk membantu mengatasi ketidakpastian penghasilan rumah tangga, meskipun masih terbatas pada cakupan yang sempit. Berdasarkan fakta ini dapat disimpulkan bahwa pemikiran dan tindakan kolektif sangat diperlukan untuk mengefektifkan strategi guna mengatasi kesulitan-kesulitan kehidupan.

Salah satu bentuk pelibatan perempuan di dalam pembangunan berhubungan dengan peningkatan peran perempuan dalam wacana pemberdayaan ekonomi yang diupayakan melalui pengorganisasian perempuan dalam komunitas. Adapun tindakan-tindakan yang bisa dilakukan adalah peningkatan peran serta lembaga-lembaga pengembangan masyarakat yang ada mencakup tentang strategi peningkatan peran serta perempuan pesisir dan kelembagaannya dengan memperhatikan aspek-aspek teknis, ekonomi, sosial-budaya dan aspek pengelolaan sumberdaya serta penjabaran peranan tiaptiap pemangku kepentingan dalam rangka pemberdayaan masyarakat pesisir. 
Tabel 8. Optimalisasi Peran Gender Pada Rumah Tangga Nelayan Kabupaten Lamongan dan Kota Padang.

Table 8. Optimalization of Gender Role on Fishers' Family in the Lamongan District and Padang.

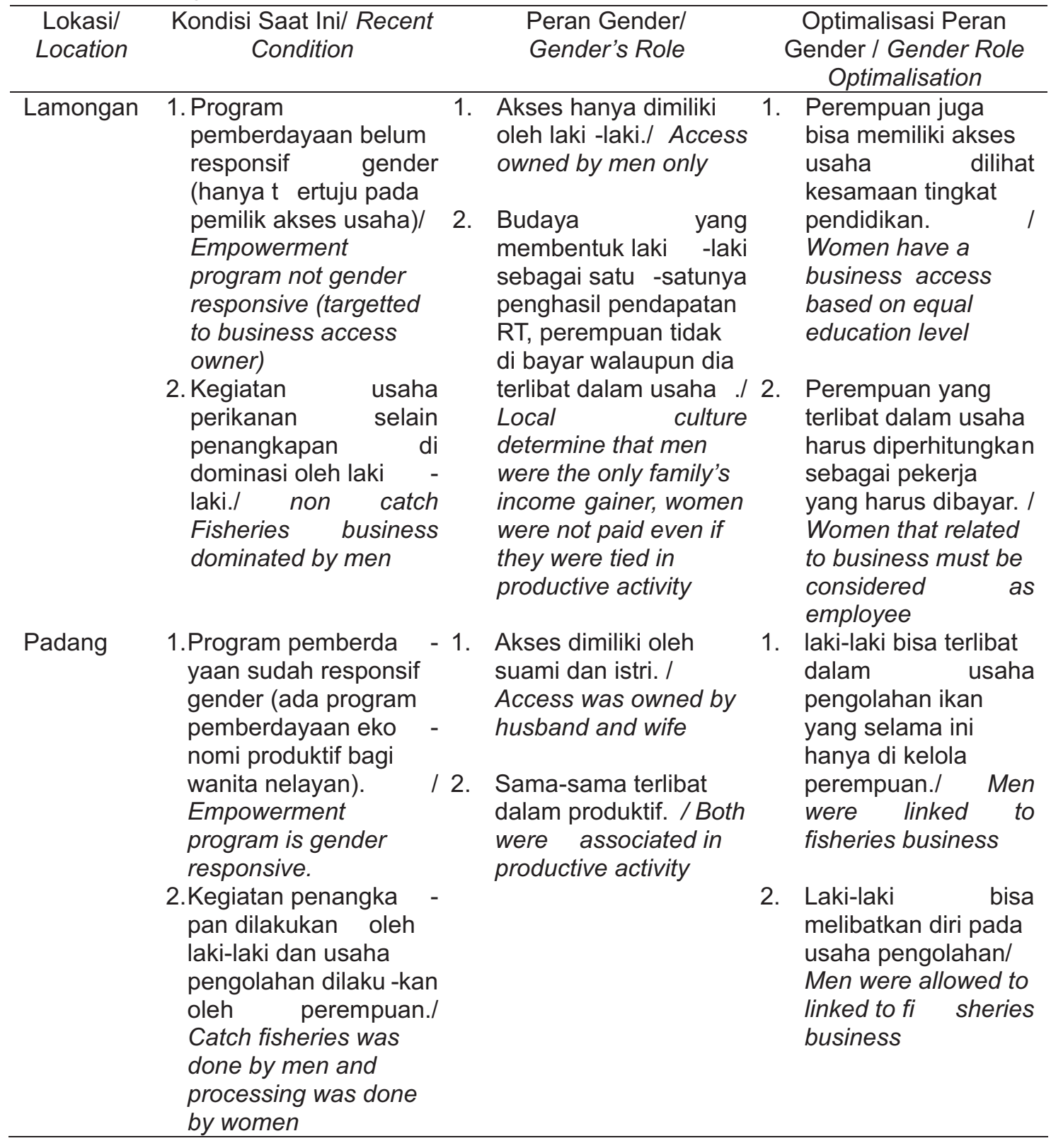

Seperti telah diungkapkan sebelumnya, hasil survai di lapangan menunjukkan bahwa hampir semua responden memiliki pemikiran yang cukup terbuka mengenai peranan suami dan istri dalam keluarga; ini berarti bahwa rekayasa sosial termasuk rekayasa gender bukan merupakan sesuatu yang mustahil. Namun, dari pengamatan terhadap aktivitas 
kehidupan sehari-hari, dapat disimpulkan bahwa rekayasa dimaksud memerlukan upaya keras untuk meningkatkan pemahaman keluarga tentang peran gender dalam mewujudkan kesejahteraan keluarga.

Strategi pengarusutamaan gender in harus diterapkan di seluruh proses lembaga pemerintah. Dengan kata lain, di dalam seluruh proses pembangunan (mulai dari perencanaan, pelaksanaan, pemantauan dan evaluasi pembangunan) harus mempertimbangkan kebutuhan laki-laki dan perempuan yang responsif gender. Tujuan PUG adalah terselenggaranya perencanaan, penyusunan, pelaksanaan, pemantauan dan evaluasi atas kebijakan dan program pembangunan nasional yang berperspektif gender dalam rangka mewujudkan kesetaraan dan keadilan gender dalam kehidupan berkeluarga, bermasyarakat, berbangsa, dan bernegara. Proses pengarusutamaan gender memerlukan data terpilah antara perempuan dan laki-laki, serta kemampuan analisis gender sehingga menghasilkan sebuah perencanaan pembangunan serta anggaran yang responsif gender (Anonimous,2004).

Bertitik tolak dari kondisi tersebut, maka perempuan pesisir perlu ditingkatkan kualitas dan kemandiriannya sehingga perempuan pesisir dapat menjadi mitra sejajar pria yang harmonis yang tidak saja berperan dalam keluarga tetapi juga dalam pembangunan perikanan dan pembangunan bangsa secara keseluruhan. Dikaitkan dengan pelaksanaan pembangunan yang semakin dilandaskan pada kapasitas sumberdaya manusia, maka pembinaan sumberdaya manusia perempuan pesisir sudah menjadi keharusan seiring dengan perkembangan kemajuan secara global.

Secara harfiah setiap anggota keluarga ingin menikmati kesejahteraan hidup tetapi masyarakat nelayan Brondong tidak tahu harus dimulai darimana dulu. Disamping itu ada kemauan keras dari masyarakat untuk hidup lebih baik. Masyarakat terlebih dahulu membentuk kelompok kerja bersama untuk lebih memudahkan akses terhadap informasi dan modal. Selain itu jika usaha dilakukan bersama, resiko-resiko usaha akan terasa sangat kecil. Pendampingan oleh instansi terkait juga dilakukan untuk kontrol kualitas dan kontinuitas usaha yang sudah dilakukan. Monitoring dan evaluasi secara berkala untuk pendampingan usaha hingga masyarakat bisa melakukan kegiatan tersebut secara mandiri dan bisa menjadi contoh bagi masyarakat yang lainnya.

Dalam hal jenis-jenis kegiatan produktif yang berpotensi untuk dikembangkan di kalangan perempuan nelayan, hasil survai di lapangan berhasil menginventarisasikannya. Tabel 9 merangkum beberapa di antara kegiatan-kegiatan produktif potensial tersebut.

Tabel 9. Jenis Kegiatan Produktif (Usaha Perikanan) yang Dapat Dilakukan Untuk Mengisi Waktu Luang di Kabupaten Lamongan.

Table 9. Type of Productive Activity (Fisheries Effort) Which Enable to Fill in Free Time in the Lamongan District.

\begin{tabular}{|c|c|c|c|}
\hline No & $\begin{array}{l}\text { Keterangan/ } \\
\text { Information }\end{array}$ & Kendala/ Constraint & Solusi/ Solution \\
\hline 1 & Permodalan/ Capital & Modal besar/ Big Capital & $\begin{array}{l}\text { Membentuk KUB untuk } \\
\text { memudahkan akses } \\
\text { terhadap informasi dan } \\
\text { modal/ Build a communal } \\
\text { business group to open }\end{array}$ \\
\hline & & & $\begin{array}{l}\text { access of infor mation and } \\
\text { capital }\end{array}$ \\
\hline
\end{tabular}


Tabel 9. Ianjutan/ Table 9. continued

\begin{tabular}{|c|c|c|c|}
\hline No & $\begin{array}{l}\text { Keterangan/ } \\
\text { Information }\end{array}$ & Kendala/ Constraint & Solusi/ Solution \\
\hline 2 & $\begin{array}{l}\text { Pengetahuan mengenai } \\
\text { aspek teknis dan variasi } \\
\text { produk/ Knowledge in } \\
\text { technical aspects and } \\
\text { product variation }\end{array}$ & $\begin{array}{l}\text { Tidak memiliki ketrampilan / } \\
\text { Low skill }\end{array}$ & $\begin{array}{l}\text { Adanya Pelatihan dan } \\
\text { ketrampilan dari instansi } \\
\text { terkait/ Training from related } \\
\text { institution }\end{array}$ \\
\hline 3 & Pemasaran/ Marketing & $\begin{array}{l}\text { Tidak memiliki pangsa } \\
\text { pasar/ No market access }\end{array}$ & $\begin{array}{l}\text { Instansi menjembatani/ } \\
\text { menjadi perantara antara } \\
\text { produsen dengan konsumen / } \\
\text { Government institution act as } \\
\text { a link between producer and } \\
\text { consumer }\end{array}$ \\
\hline 4 & $\begin{array}{l}\text { Kelembagaan } \\
\text { penyuluh/ Counceling } \\
\text { institution }\end{array}$ & $\begin{array}{l}\text { Kurang aktifnya tenaga } \\
\text { penyuluh dalam melaku - } \\
\text { kan pendampingan/ } \\
\text { inactive councellor in } \\
\text { councelling activity }\end{array}$ & $\begin{array}{l}\text { Melakukan penataan } \\
\text { kelembagaan penyuluh/ } \\
\text { Revitalization of councelling } \\
\text { institution }\end{array}$ \\
\hline 5 & $\begin{array}{l}\text { Keberlanjutan dan } \\
\text { diversifikasi usaha } \\
\text { Business continuity and } \\
\text { diversivication }\end{array}$ & $\begin{array}{l}\text { Tidak ada kelanjutan } \\
\text { latihan/ No training } \\
\text { continuity }\end{array}$ & $\begin{array}{l}\text { Monitoring dan evaluasi yang } \\
\text { dilakukan secara berkala } \\
\text { Regular monitoring and } \\
\text { evaluation }\end{array}$ \\
\hline
\end{tabular}

\section{KESIMPULAN DAN IMPLIKASI KEBIJAKAN}

Keterlibatan istri nelayan Padang di sektor produktif menghasilkan pendapatan sedangkan istri nelayan Lamongan tidak menghasilkan pendapatan karena dianggap membantu pekerjaan suami. Pada masyarakat nelayan Brondong, terlihat lakilaki memiliki beban lebih daripada perempuan, sebaliknya di masyarakat nelayan Padang justru isrti memiliki beban lebih dan beban ganda. Keputusan di sektor domestik di dominasi oleh istri sedangkan keputusan di sektor produktif nelayan Lamongan di dominasi suami dan di masyarakat nelayan Padang adalah keputusan bersama.

Optimalisasi peran gender pada masyarakat nelayan Brondong perlu dilakukan melalui pelibatan peran perempuan sedangkan pada masyarakat nelayan Padang, peran suami dalam usaha pengolahan perlu dilibatkan. Karena gender merupakan konstruksi sosial budaya maka gender tidak universal atau seragam melainkan relatif pada konteks sosial budaya masyarakatnya. Maka arahan kebijakan yang sesuai untuk neyalan Brondong adalah pemberdayaan ekonomi perempuan karena mereka memiliki waktu luang 7,47 jam/hari $(31,11 \%)$. Sedangkan untuk masyarakat nelayan Padang, pemberdayaan lebih kearah peningkatan pemahaman konsep gender dalam mewujudkan kesejahteraan keluarga.

\section{DAFTAR PUSTAKA}

Anonimous,2004. Panduan Pelaksanaan Pengarusutamaan Gender (PUG) Lingkup Departemen Kehutanan. Departemen Kehutanan. --,2002. Perencanaan Perperspektif Gender: Bahan Informasi Pengarusutamaan Gender, Edisi ke-2, Buku 3, Kantor Menteri Negara 
Pemberdayaan Perempuan RI, Jakarta. ,2005. Kebijakan dan Strategi Pembangunan Pemberdayaan Perempuan. Kantor Menteri Negara Pemberdayaan Perempuan RI, Jakarta. ,2006. Buku Tahunan Statistik Perikanan Tahun 2006. Dinas Perikanan, Kelautan dan Peternakan Kabupaten Lamongan Jawa Timur. Lamongan

Arifin, H., 2003. Perempuan, Kemiskinan dan Pengambilan Keputusan. Jurnal Analisis Sosial. Vol. 8, No.2. Oktober 2003. Bandung

Ervita dan Puji Utami,2007. Memahami Gender dan Kekerasan terhadap Perempuan. Rifka Annisa Women's Crisis Center. Jakarta. Tidak dipublikasikan.

Indriatmoko,Y., 2007. Dari desa ke desa (Dinamika Gender Dan Pengelolaan Kekayaan Alam). Subur Printing. Jakarta. Nasution,Z,dkk., 2007. Peran Gender Dalam Rumah Tangga Kelautan dan Perikanan, Laporan Teknis, BBRSEKP. Jakarta. Tidak dipublikasikan.

BBBRSEKP,2007. Daya Beli Masyarakat Kelautan dan Perikanan. Dilaporkan ke Kepala BRKP. Jakarta. Tidak dipublikasikan.

Satria, A. 2008. Negeri Bahari yang Melupakan Nelayan. Koran Kompas terbit Senin 09/06/2008. 